\title{
Distribution and swimming behaviour of Neomysis integer (Peracarida: Mysidacea) in response to gradients of dissolved oxygen following exposure to cadmium at environmental concentrations
}

\author{
S. D. Roast ${ }^{1}$, J. Widdows ${ }^{2}$, M. B. Jones ${ }^{1, *}$ \\ ${ }^{1}$ Plymouth Environmental Research Centre, Department of Biological Sciences, University of Plymouth, Drake Circus, \\ Plymouth, Devon PL4 8AA, United Kingdom \\ ${ }^{2}$ Plymouth Marine Laboratory, Prospect Place, West Hoe, Plymouth, Devon PL1 3DH, United Kingdom
}

\begin{abstract}
Neomysis integer (Peracarida: Mysidacea) is a dominant member of the hyperbenthos of the upper reaches of European estuaries. They are highly dynamic environments that experience, amongst other things, large-scale fluctuations in dissolved oxygen (DO) concentration. The present study reports the tolerance and swimming responses of $N$. integer to hypoxia, together with the modifying effects of environmentally realistic cadmium concentrations ( 0 to $1.0 \mu \mathrm{g} \mathrm{Cd}^{2+} \mathrm{l}^{-1}$ ). The tolerance $\left(\mathrm{ET}_{50}\right.$, or time taken for $50 \%$ of mysids to show an effect) of $\mathrm{N}$. integer to hypoxia was ca. 5 min at $20 \%$ saturation $\left(59.4 \mathrm{\mu mol} \mathrm{O}_{2} \mathrm{l}^{-1}\right)$; however, a $7 \mathrm{~d}$ pre-exposure to $0.5 \mathrm{\mu g} \mathrm{Cd}^{2+} \mathrm{l}^{-1}$ reduced the $\mathrm{ET}_{50}$ to ca. 3 min. Mysids did not avoid areas of severe hypoxia ( $<10 \%$ saturation) and made excursions of short duration (ca. $30 \mathrm{~s}$ ) into such areas. Following cadmium exposure, however, mysids did avoid areas of hypoxia. When challenged with a current velocity of $6 \mathrm{~cm} \mathrm{~s}^{-1}$ (normal for their natural habitat), mysids showed positive rheotaxic behaviour, but as DO concentration was progressively decreased, fewer mysids swam forward into the current and more maintained position. Fewer cadmium-exposed mysids showed positive rheotaxis than control mysids, and decreasing DO concentration had no significant effect on the proportion of mysids exhibiting this behaviour. The results are discussed in terms of how DO concentrations might affect mysid distributions in the natural environment and how cadmium exposure might disrupt these responses.
\end{abstract}

KEY WORDS: Estuarine mysids $\cdot$ Hypoxia $\cdot$ Behaviour $\cdot$ Cadmium

\section{INTRODUCTION}

The upper regions of estuaries are dynamic environments where the conflicting forces of river and tidal flow cause large-scale and regular fluctuations in physico-chemical conditions, particularly current velocity, salinity, temperature, turbidity and dissolved oxygen (DO) (McLusky 1989, Little 2000). Such changeable conditions impose acute demands on the physiology of any organism inhabiting upper estuaries,

${ }^{*}$ Corresponding author. E-mail: m.jones@plymouth.ac.uk although such demands may be minimised by the plasticity of an organism's physiology (Hagerman 1998) and behaviour. In Europe, the mysid Neomysis integer (Peracarida: Mysidacea) is a common inhabitant of upper estuarine regions where it dominates the hyperbenthos (Mees et al. 1994, Mees \& Jones 1997). Both salinity and temperature effect changes in the oxygen consumption rate of $N$. integer in the laboratory, such that increasing temperature and decreasing salinity cause an increase in oxygen consumption (Roast et al. 1999). In the natural estuarine environment, however, changes in the rate of oxygen consumption over a tidal cycle are relatively minor due to reciprocal effects of 
temperature and salinity on respiration, and feeding, of this species (Roast et al. 1999, 2000a). Although temperature and salinity may fluctuate widely over a tidal cycle (8 to $15^{\circ} \mathrm{C}$ and 1 to 33 , respectively), these environmental factors do not appear to affect the position maintenance behaviour of $N$. integer (Roast et al. 1998). Whether any other physico-chemical variables affect position maintenance behaviour is yet to be determined. Where upstream seawater flow is balanced by downstream river flow in estuaries, suspended sediment accumulates creating a maximum turbidity zone (MTZ) (e.g. Eyre 1998, Uncles et al. 1998). As the leading edge of the tide moves up and down the upper part of an estuary, so too does the MTZ (Eyre 1998). Intense microbial activity, associated with such turbidity, can decrease significantly the concentration of DO in the MTZ, causing an 'oxygen sag' which moves up and down the estuary with the MTZ (Fig. 1). As the MTZ and, therefore, the oxygen sag usually occurs towards the upper reaches of an estuary, the region usually inhabited by $N$. integer (Roast et al. 1998), the present study examined the responses of $N$. integer to hypoxia and gradients of DO to establish whether this factor partially influences its distribution.

In addition to the extreme variability in environmental conditions due to natural processes, upper estuaries are often the first areas to receive anthropogenic inputs. Upper estuarine areas may be particularly susceptible to trace metal influences because freshwater dominates

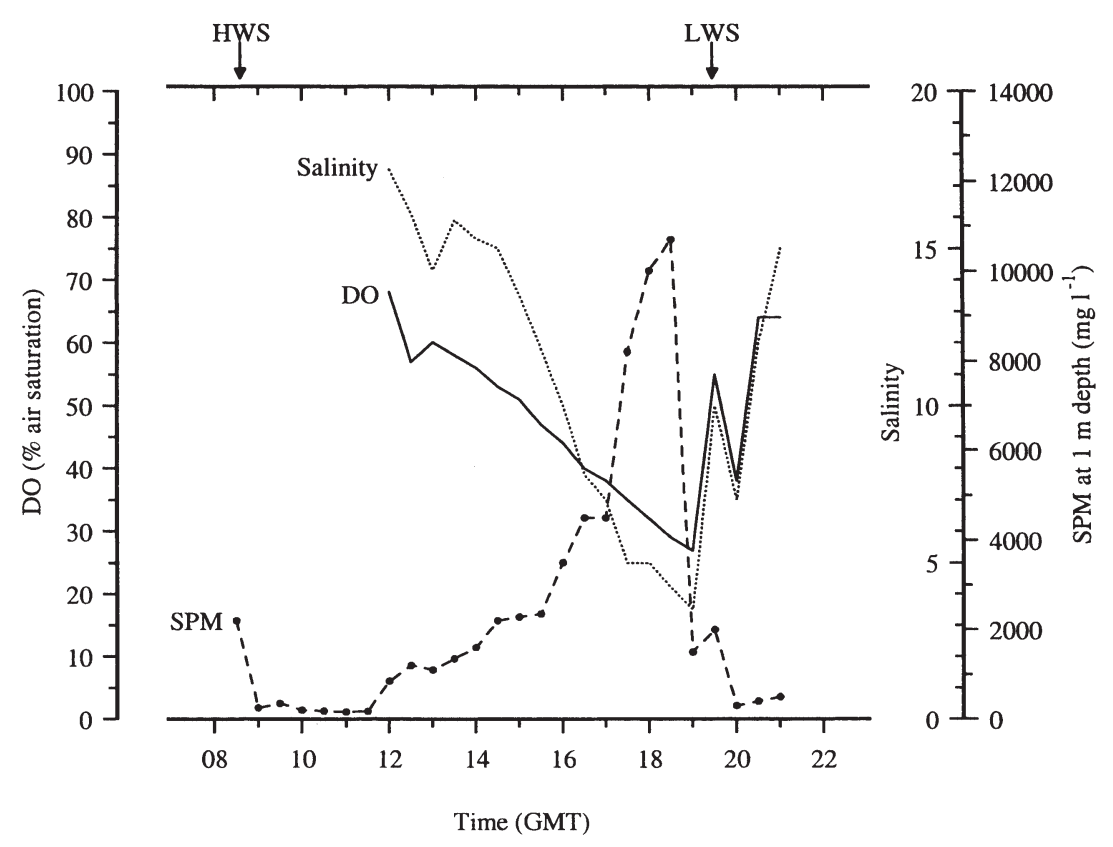

Fig. 1. Schematic representation of the relationship between salinity, turbidity (suspended particulate matter; SPM) and dissolved oxygen (DO) concentration in a UK estuary (Humber-Ouse). (After Uncles et al. 1998) for much of the time and water chemistry, particularly low salinity/chlorinity, significantly affects the bioavailability of metals to estuarine biota (Wright 1995, Rainbow 1997). Cadmium (Cd) reduces the swimming speed and rheotaxic response of Neomysis integer (Roast et al. 2001), and the implications of such disruption of swimming ability include increased predation and/or displacement from optimum sites within the estuary (Roast et al. 2001). The present study, therefore, investigated the additional effect of pre-exposure to environmentally realistic concentrations of $\mathrm{Cd}$ on the behavioural response of $N$. integer to hypoxia.

\section{MATERIALS AND METHODS}

Mysid collection and maintenance. During May 2000, adult mysids were collected from the southern side of Terras Bridge, East Looe River Estuary, Cornwall (United Kingdom) (National grid reference SX 532256) by sweeping a Freshwater Biological Association (UK) dip net (1 mm mesh) along the water's edge at low tide. Mysids were transferred to the laboratory in habitat water (salinity $\approx 1$ ) and placed in a 401 holding tank at a salinity of $10 \pm 1$ (prepared by combining filtered offshore seawater with distilled water) in a constant-temperature room $\left(15 \pm 1^{\circ} \mathrm{C}\right)$. All experiments were conducted at a salinity of 10 and a temperature of $15^{\circ} \mathrm{C}$. An Eheim ${ }^{\circledR}$ filter (pumping $440 \mathrm{l} \mathrm{h}^{-1}$ ) maintained water quality and provided gentle water movement. Lighting, provided at ambient laboratory levels by fluorescent lights, was controlled by a time switch to produce a 16 h light:8 h dark photoperiod. Mysids were fed ad libitum on $<48 \mathrm{~h}$ old Artemia sp. nauplii (var.: Great Lakes, Utah), hatched in the laboratory from cysts.

Cd exposure. Prior to each experiment, mysids were exposed to sublethal concentrations of $\mathrm{Cd}$ for $7 \mathrm{~d}$.

Cd speciation: The percentage of free (aqueous) $\mathrm{Cd}$ available at the exposure salinity (10) was modelled using MINEQL ${ }^{\mathrm{TM}}$ computer software. Instant Ocean ${ }^{\mathrm{TM}}$ synthetic seawater was used for the $\mathrm{Cd}$ exposure to ensure the exact concentrations of seawater constituents were entered into the model. The percentage of free $\mathrm{Cd}$ at the experimental salinity was modelled to be $14.8 \%$, which agrees closely with published speciation estimates (Turner et al. 1981, DeLisle \& Roberts 1994). This estimate was used 
in all chemical calculations such that, hereafter, all $\mathrm{Cd}$ concentrations refer to the concentration of free metal ion, generally accepted as the toxic species (e.g. Wright 1995, Rainbow 1997).

Cd exposure: For each experiment, 3 concentrations of $\mathrm{Cd}\left(0.1,0.5\right.$ and $\left.1.0 \mu \mathrm{g} \mathrm{Cd}^{2+}{ }_{(\mathrm{aq})}{ }^{-1}\right)$ and a Cd-free (i.e. no added $\mathrm{Cd}$ ) control were used. For each exposure solution, $22.6 \mathrm{~g}$ of Instant Ocean salts were dissolved in $1.5 \mathrm{l}$ of double-distilled, de-ionised water by stirring at high speed. The appropriate volume of $0.1 \mathrm{~g} \mathrm{l}^{-1} \mathrm{Cd}$ stock (13.5, 68 and $135 \mu \mathrm{l}$ for 0.1, 0.5 and $1.0 \mu \mathrm{g} \mathrm{Cd}^{2+} \mathrm{l}^{-1}$ respectively) was injected via a Gilson pipette into the vortex of the dilution water and allowed to mix for 5 min. Finally, the solution was made up to a premarked 21 line and allowed a final 5 min before being decanted into a $2 \mathrm{l}$ tall-form glass beaker. Twenty mysids of equal length were placed in each beaker. Mysids were fed ad libitum with $<48 \mathrm{~h}$ old Artemia sp., and solutions were aerated with filtered, compressed air via a glass pipette. Mortalities occurring during the course of the exposure period were recorded and dead mysids were removed from the beaker.

Median time for effect. Mysids were exposed to hypoxia to establish the median time for effect $\left(\mathrm{ET}_{50}\right)$. Under extreme conditions of hypoxia (10\% air saturation), Neomysis integer stopped swimming and sank, tail first, to the bottom of the test vessel, where they performed several escape responses (tail flexions) before lying motionless. At this stage, however, the mysids were not dead, as once the solution was reaerated, they revived and started normal swimming behaviour. Clearly, in this experiment mortality cannot be defined accurately by visual inspection, therefore, rather than performing median lethal time $\left(\mathrm{LT}_{50}\right)$ tests, median times for effect $\left(\mathrm{ET}_{50}\right)$ were calculated. An $\mathrm{ET}_{50}$ is the time taken for $50 \%$ of the mysids to show an effect of hypoxia; in this case the 'effect' was defined as the point when the mysid sank to the bottom of the vessel and no longer performed escape responses.

A $500 \mathrm{ml}$ respirometry chamber was filled with dilute seawater (salinity $=10$ ) of the required DO concentration. DO concentrations, manipulated by bubbling oxygen-free nitrogen (OFN) and filtered air through the test chamber, were measured by Strathkelvin oxygen electrodes and meters, coupled to a personal computer via a data logger. Following exposure to $\mathrm{Cd}$, 10 mysids were introduced into the vessel via a widebore tube ( $1 \mathrm{~cm}$ bore; $10 \mathrm{~cm}$ length). This entry method ensured all mysids were placed in the vessel at exactly the same time and exposure of the solution to the air was minimal. Introduction of the mysids took less than $20 \mathrm{~s}$ but caused an increase of ca. $5 \%$ air saturation in the DO concentration (due to the water the mysids were transferred in). This increase was accounted for by establishing the exposure water at $5 \%$ air saturation lower than that required. As soon as the mysids were placed in the vessel, a stop-watch was started and the hole through which they were introduced was plugged. The time taken for each mysid to show the effects of hypoxia (defined above) was recorded. Five replicates were made at each DO concentration (i.e. $\mathrm{n}=50$ per DO concentration). DO concentrations used were 20,25 and $30 \%$ air saturation (i.e. 59.4, 74.2 and $89.0 \mathrm{\mu mol} \mathrm{O}_{2} \mathrm{l}^{-1}$ respectively).

Effect of DO on mysid swimming behaviour. Effect of hypoxia when swimming against a current: The effect of DO concentration on mysid swimming was investigated using an annular flume (Widdows et al. 1998). Following the $7 \mathrm{~d} \mathrm{Cd}$ exposure period, 20 mysids were placed in the flume (salinity $=10 \pm 1 ; 15 \pm 1^{\circ} \mathrm{C}$ ) and kept for $30 \mathrm{~min}$, and the drive-plate was started to create a current velocity of $6 \mathrm{~cm} \mathrm{~s}^{-1}$ (a velocity against which ca. $70 \%$ are able to swim; Roast et al. 1998). After $5 \mathrm{~min}$ at the new current velocity, each mysid was scored according to direction facing (into/with the direction of flow) and their direction of movement (into/with the flow, or maintaining position) (Roast et al. 1998). Concentration of DO was then reduced rapidly to $90 \%$ air saturation by bubbling OFN through the water; a Strathkelvin 1302 oxygen electrode mounted through a port in the side of the flume measured DO concentration. Mysids were given 5 min at the new conditions and swimming behaviour was again recorded. This protocol was repeated at $10 \%$ decrements of DO down to, and including, 30\% air saturation.

Mysid distribution along an oxygen gradient: The distribution of Neomysis integer along an oxygen gradient was investigated using a straight-channel flume comprising a Perspex tube with a reservoir at each end (Fig. 2). A gradient of DO was established by bubbling OFN through the water in one of the reservoirs and filtered air through the water in the other reservoir (Fig. 2). To improve the gradient, a peristaltic pump was used to draw water along the tube. Using this method, a gradient of 85 to $10 \%$ air saturation was established along the length of the tube. The tube was scored every $100 \mathrm{~mm}$ along its length to mark 6 sections and a Strathkelvin 1302 oxygen electrode was mounted within each section to measure DO concentrations (Fig. 2). The oxygen electrodes were connected, via Strathkelvin 781 oxygen meters, to a computer and DO concentrations were recorded continuously for the duration of each experiment. At the start of each experiment, 20 mysids of similar size (14 \pm $1 \mathrm{~mm}$ from the anterior margin of the rostrum to the tip of the telson) were placed carefully in the Perspex tube and maintained at $100 \%$ air saturation. A net (1 $\mathrm{mm}$ mesh) was placed over each end of the tube to 


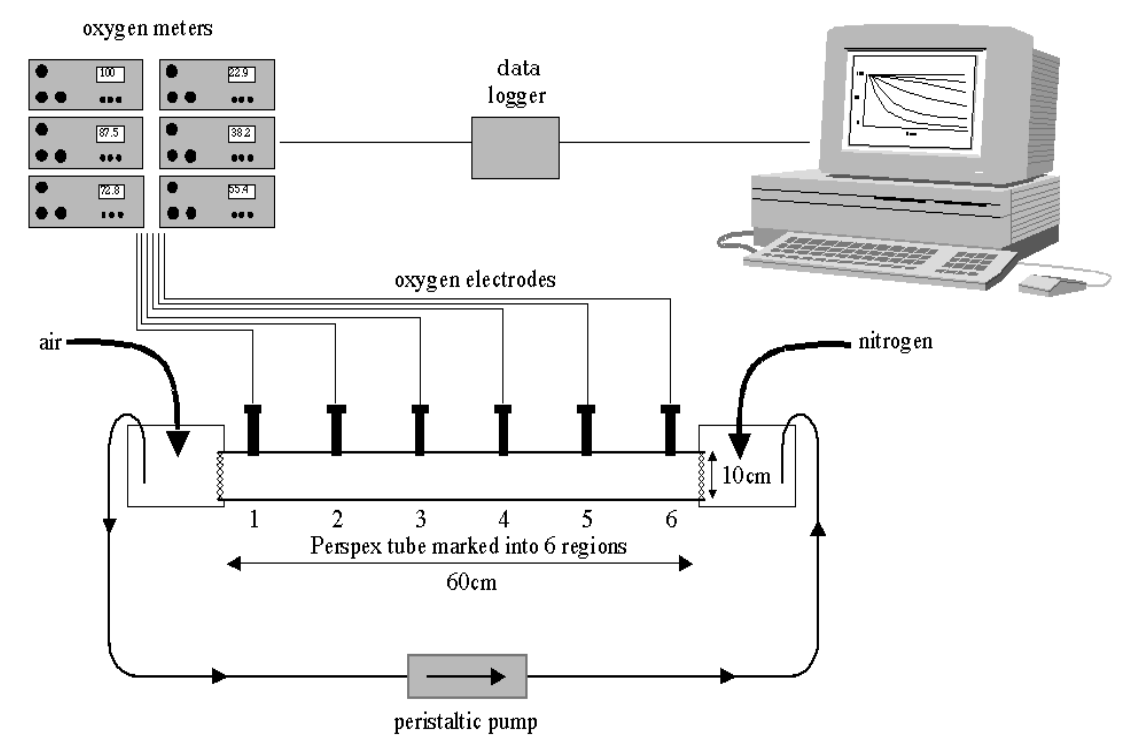

Fig. 2. Experimental set-up for generating and maintaining an oxygen gradient in seawater

prevent mysids from escaping. Mysids were left for 30 min to distribute themselves along the tube and, after this period, OFN was bubbled into the reservoir and the peristaltic pump started to establish the DO gradient. Mysid distribution was recorded every $5 \mathrm{~min}$ as the number of mysids within each of the six $100 \mathrm{~mm}$ tube sections; DO concentration was recorded at $1 \mathrm{~min}$ intervals so that mysid distribution could be correlated with DO concentration.

Statistical analysis. Median time for effect: For each experiment, the percentage of mysids showing effects of hypoxia was transformed into probits and plotted against time. Linear regression was used to calculate the $\mathrm{ET}_{50}$, which corresponds to the time equal to a probit value of 5. Mean $\mathrm{ET}_{50}$ values and corresponding $95 \%$ confidence intervals were calculated for each DO/Cd exposure concentration.

Swimming against a current: Proportions of mysids exhibiting each behavioural type were arc-sine squareroot transformed (to account for very small proportions) and examined statistically by 1- and 2-way analysis of variance (ANOVA) (Roast et al. 1998).

Table 1. Neomysis integer. Effect of $7 \mathrm{~d}$ pre-exposure to $\mathrm{Cd}$ on median time for effect $\left(\mathrm{ET}_{50}\right.$ i hh:mm:ss) of hypoxia; no effect was recorded within $24 \mathrm{~h}$ at $>40 \%$ air saturation. DO = dissolved oxygen ( $\%$ air saturation). $\pm 95 \%$ confidence intervals $(n=10)$

\begin{tabular}{|c|c|c|c|c|c|c|}
\hline \multirow{2}{*}{$\frac{\mathrm{DO}}{40}$} & \multicolumn{2}{|c|}{- Control -} & \multicolumn{2}{|c|}{$-0.5 \mu \mathrm{g} \mathrm{Cd}^{2+} \mathrm{l}^{-1}-$} & \multicolumn{2}{|c|}{$-1.0 \mu \mathrm{g} \mathrm{Cd}^{2+} \mathrm{l}^{-1}-$} \\
\hline & $>24: 00: 00$ & - & $>12: 00: 00$ & - & $>12: 00: 00$ & - \\
\hline 30 & $>24: 00: 00$ & - & 06:30:00 & $\pm 00: 00: 50$ & 05:55:00 & $\pm 00: 58: 00$ \\
\hline 20 & 00:04:50 & $\pm 00: 00: 28$ & $00: 02: 55$ & $\pm 00: 00: 39$ & 00:03:10 & $\pm 00: 00: 44$ \\
\hline
\end{tabular}

Distribution along a gradient: Numbers of mysids in each section of the tube were transformed into proportions and plotted against DO concentration. Linear regression was used to fit a line through the data points and analysis of covariance (ANCOVA) used to identify differences in the attributes of the best-fit line. Replicate data from each of the $\mathrm{Cd}$ treatments were combined and plotted as 1 data set to allow ANCOVA between treatments.

\section{RESULTS}

\section{Median time for effect}

Mysids were able to survive DO concentrations down to $30 \%$ air saturation for more than $24 \mathrm{~h}$, but at $20 \%$ air saturation the $\mathrm{ET}_{50}$ was reduced significantly (Table 1). Exposure to $\mathrm{Cd}$ reduced the $\mathrm{ET}_{50}$ at each DO concentration. For example, at $30 \%$ air saturation, $\mathrm{ET}_{50}$ values of $6 \mathrm{~h} 30 \mathrm{~min}$ and $5 \mathrm{~h} 50$ min were recorded at 0.5 and $1.0 \mu \mathrm{g} \mathrm{Cd}^{2+} \mathrm{l}^{-1}$ respectively (Table 1). At $30 \%$ air saturation, the hypoxia response was concentration dependent, but not at $20 \%$ air saturation (Table 1).

\section{Swimming against a current}

At a current velocity of $6 \mathrm{~cm} \mathrm{~s}^{-1}$, most control mysids swam forward into the current (Type 1; Fig. 3). As the DO concentration decreased, however, fewer mysids were able to swim forward into the current and, at $30 \%$ air saturation, no mysids were able to swim into the current (Fig. 3). In contrast, as the DO concentration decreased, the proportion of mysids maintaining position increased from ca. 0.25 at $100 \%$ air saturation to 0.90 at $30 \%$ air saturation (Type 2; Fig. 3). At $30 \%$ air saturation, there was a significant increase in the proportion of mysids facing into, but being swept by, the current (Type 3; Fig. 3). Hypoxia, however, had no effect on the proportion of mysids swimming with the current (Type 4; Fig. 3). Swimming behaviour was not examined at $<30 \%$ air saturation since Neomysis integer showed poor tolerance to such low DO concentrations (Table 1). 


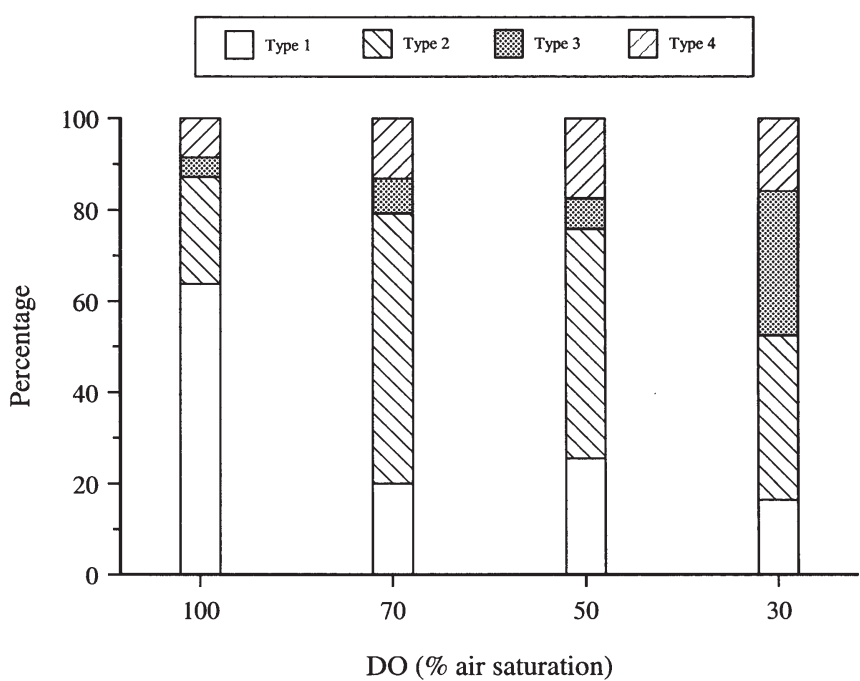

Fig. 3. Neomysis integer. Swimming responses when challenged with progressive hypoxia and a current velocity of $6 \mathrm{~cm} \mathrm{~s}^{-1}$ in an annular flume. Type $1=$ swimming forward into the current; Type $2=$ maintaining position; Type $3=$ facing into, but being swept by, the current; Type $4=$ facing with the current (after Roast et al. 1999). ( $n=100)$

\section{Effect of pre-exposure to $\mathrm{Cd}$ on mysid response to DO in flume}

There were significant effects of pre-exposure to $\mathrm{Cd}$ on the swimming behaviour of mysids exposed to hypoxia in the flume (Figs. $4 \& 5$ ). At DO concentrations from 100 to $60 \%$ air saturation, more control mysids swam forward into the current than Cdexposed animals (95\% confidence intervals; Fig. 4);

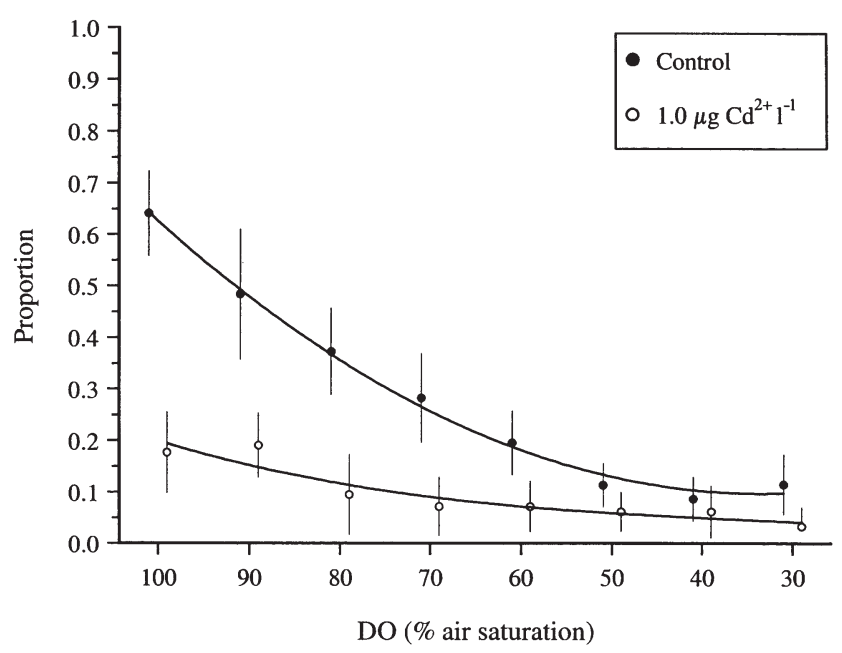

Fig. 4. Neomysis integer. Effect of $7 \mathrm{~d}$ pre-exposure to $\mathrm{Cd}$ on the proportion swimming forward into the current. ( $\mathrm{n}=100$ for each data set). Error bars correspond to $\pm 95 \%$ confidence intervals

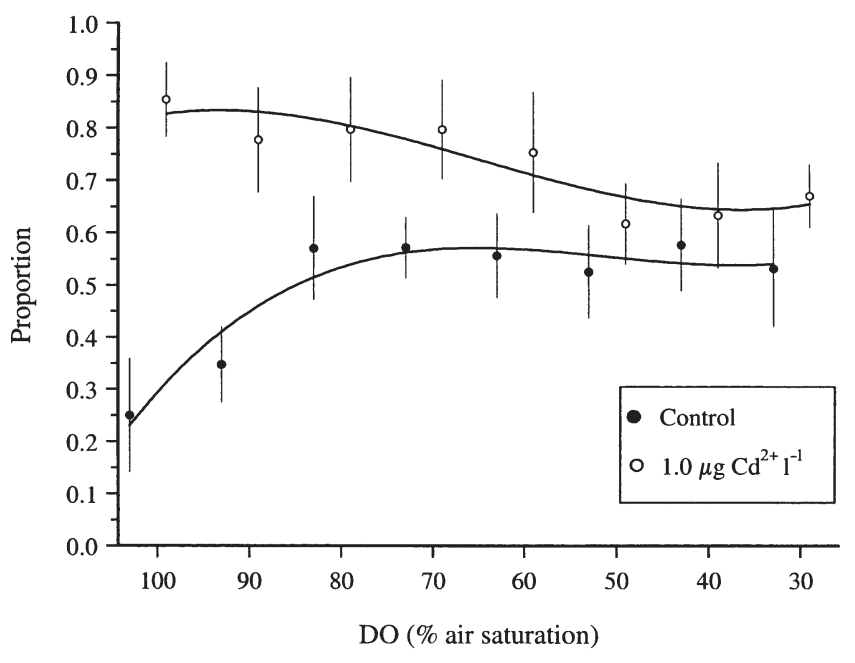

Fig. 5. Neomysis integer. Effect of $7 \mathrm{~d}$ pre-exposure to Cd on the proportion maintaining position $(\mathrm{n}=100$ for each data set). Error bars correspond to $\pm 95 \%$ confidence intervals

but below $60 \%$ air saturation, there was no significant difference in the frequency of this behavioural type (95\% confidence intervals; Fig. 4). In contrast, significantly more Cd-exposed mysids maintained position at DO concentrations from 100 to $60 \%$ air saturation compared with control mysids (95\% confidence intervals; Fig. 5). Again, below $60 \%$ air saturation, there was no significant difference in the frequency of position maintenance exhibited by control or Cd-exposed mysids (95\% confidence intervals; Fig. 5).

\section{Distribution along a gradient}

Interestingly, in view of the results from the $\mathrm{ET}_{50}$ study, control mysids showed no clear response to a gradient of DO (Fig. 6). Mysids were recorded for the duration of the experiment (90 $\mathrm{min}$ ) in those sections of the tube where DO concentrations were as low as 10 or $20 \%$ air saturation, i.e. lower than those shown to cause effects (Fig. 6). However, although mysids would still enter regions of critical hypoxia, they did not remain in these regions for long periods of time, instead they moved in and out of such areas for periods of no more than 20 to $30 \mathrm{~s}$.

\section{Effect of pre-exposure to Cd on mysid response to DO gradient}

Pre-exposure to $\mathrm{Cd}$ for $7 \mathrm{~d}$ had significant effects on the behavioural responses of Neomysis integer to an oxygen gradient, whereby mysids exposed to $\mathrm{Cd}$ avoided areas of low DO (Fig. 7). This response was 

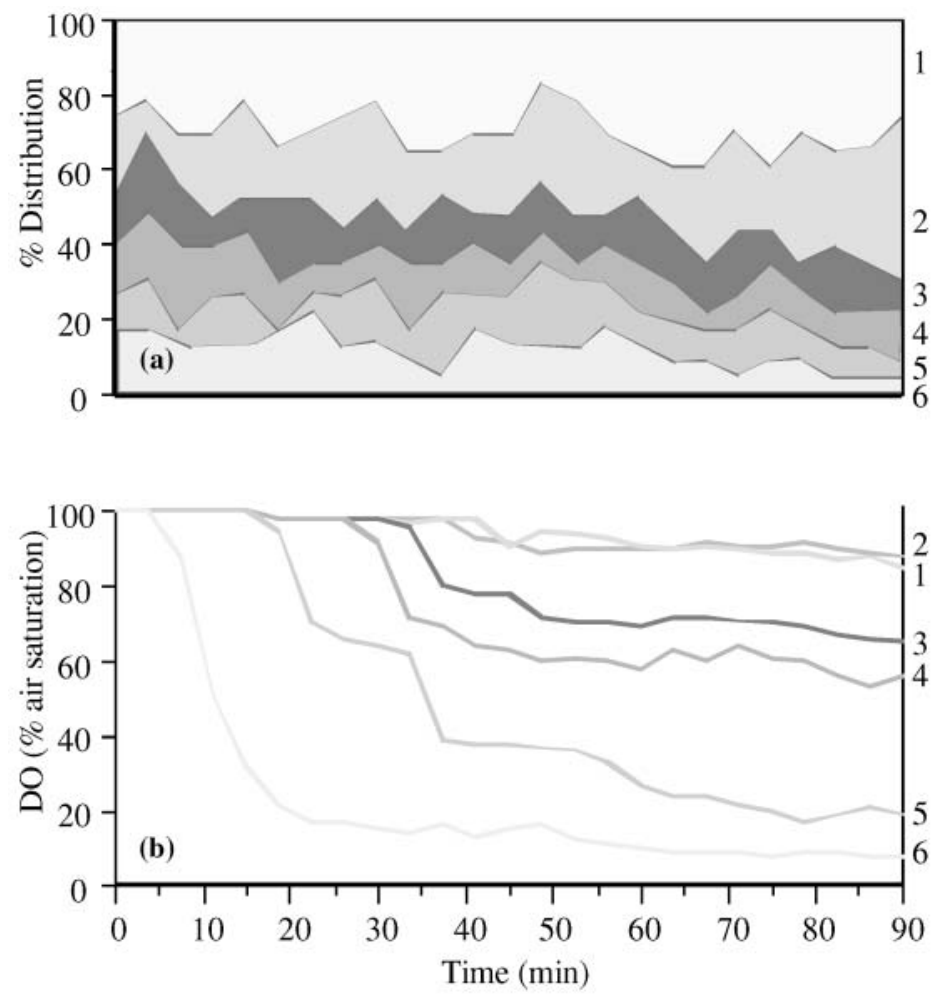

by the increase in numbers of mysids in the normoxic sections of the tube (e.g. section 1; Fig. 9). Although there were significant differences between mysids exposed to 0.1 and $0.5 \mu \mathrm{g} \mathrm{Cd}^{2+} \mathrm{l}^{-1}$ (ANCOVA, F-ratio $=$ $9.8, \mathrm{df}=1,36, \mathrm{p}=0.003$ ), there was no significant difference in the rate of migration away from hypoxia for mysids exposed to 0.5 or $1.0 \mu \mathrm{g} \mathrm{Cd}^{2+} \mathrm{l}^{-1}$ (ANCOVA, Fratio $=1.67, \mathrm{df}=1,36, \mathrm{p}=0.19$ ).

\section{DISCUSSION}

In general, Neomysis integer inhabits the very upper part of estuaries in the region of the freshwater/seawater interface (Mees et al. 1994, Roast et al. 1998), which may experience large-scale changes in DO concentration (e.g. Uncles et al. 1998, Irigoien et al. 1999, Mitchell et al. 1999). The present study has shown that $N$. integer is sensitive to hypoxia. Although results are presented as median time for effect $\left(\mathrm{ET}_{50}\right)$, the results might be considered the same as a median lethal time $\left(\mathrm{LT}_{50}\right)$ when predicting environmental consequences. For example, in the present study, we have used the criterion of sinking motionless to the bottom of the vessel as a measured 'effect' and, although $N$. integer
Fig. 6. Neomysis integer. Distribution in response to a gradient of DO. (a) Percentage areagram of mysid distribution in each section of the tube (numbered area corresponds to tube region in Fig. 2); (b) concentration of DO ( $\%$ air saturation). $(\mathrm{n}=100)$

concentration-specific and only mysids exposed to $\geq 0.5 \mu \mathrm{g} \mathrm{Cd}^{2+} \mathrm{l}^{-1}$ showed disrupted behaviour. Comparison of the regression lines showed significant differences between the slopes of the distribution lines for control mysids and mysids exposed to $\geq 0.5 \mu \mathrm{g} \mathrm{Cd}^{2+} \mathrm{l}^{-1}$ (ANCOVA, F-ratio = 9.2 , df $=1,36, p=0.005)$, but not between control mysids and mysids exposed to $0.1 \mu \mathrm{g} \mathrm{Cd}^{2+} \mathrm{l}^{-1}$ $($ ANCOVA, $F$-ratio $=0.14, \mathrm{df}=1,36, \mathrm{p}=0.7)$. As the concentration of DO in Region 6 of the tube (the most hypoxic region) decreased, mysids exposed to $\geq 0.5 \mu \mathrm{g} \mathrm{Cd}^{2+} \mathrm{l}^{-1}$ migrated out of this section so that after $55 \mathrm{~min}$ there were no mysids present in this region of the tube (Fig. 8). In contrast, control mysids and mysids exposed to $0.1 \mathrm{\mu g} \mathrm{Cd}^{2+} \mathrm{l}^{-1}$ remained in Region 6 of the tube throughout the experiment (albeit for only short time periods; see above) (Fig. 8). In Region 6 of the tube, DO decreased to $10 \%$ air saturation after $30 \mathrm{~min}$. Cd-exposed mysids, therefore, responded to this severe hypoxia within $10 \mathrm{~min}$ (only $10 \%$ of mysids were recorded in Region 6 at $40 \mathrm{~min}$ ) (Fig. 8). The movement of Cd-exposed mysids away from areas of hypoxia is confirmed
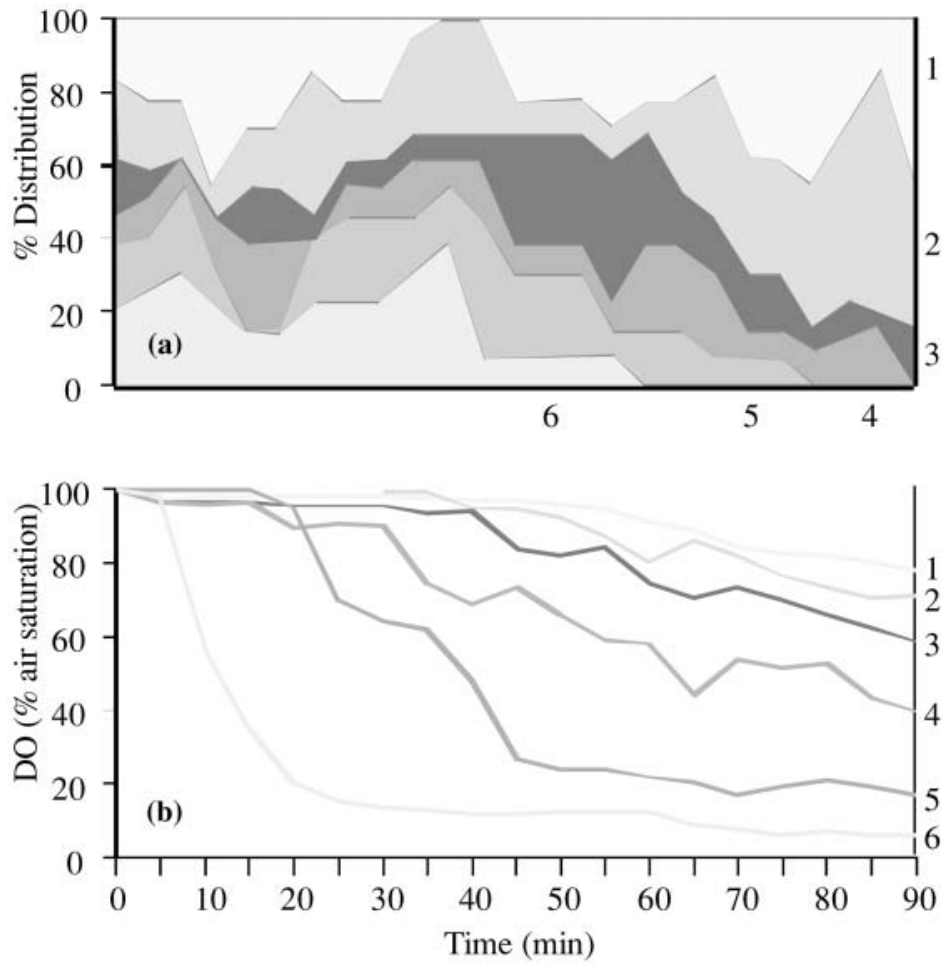

Fig. 7. Neomysis integer. Effect of $7 \mathrm{~d}$ pre-exposure to $\mathrm{Cd}$ on distribution in response to a gradient of DO. (a) Percentage areagram of mysid distribution in each section of tube (numbered area corresponds to tube region in Fig. 2); (b) concentration of DO ( $\%$ air saturation). $(\mathrm{n}=100)$ 

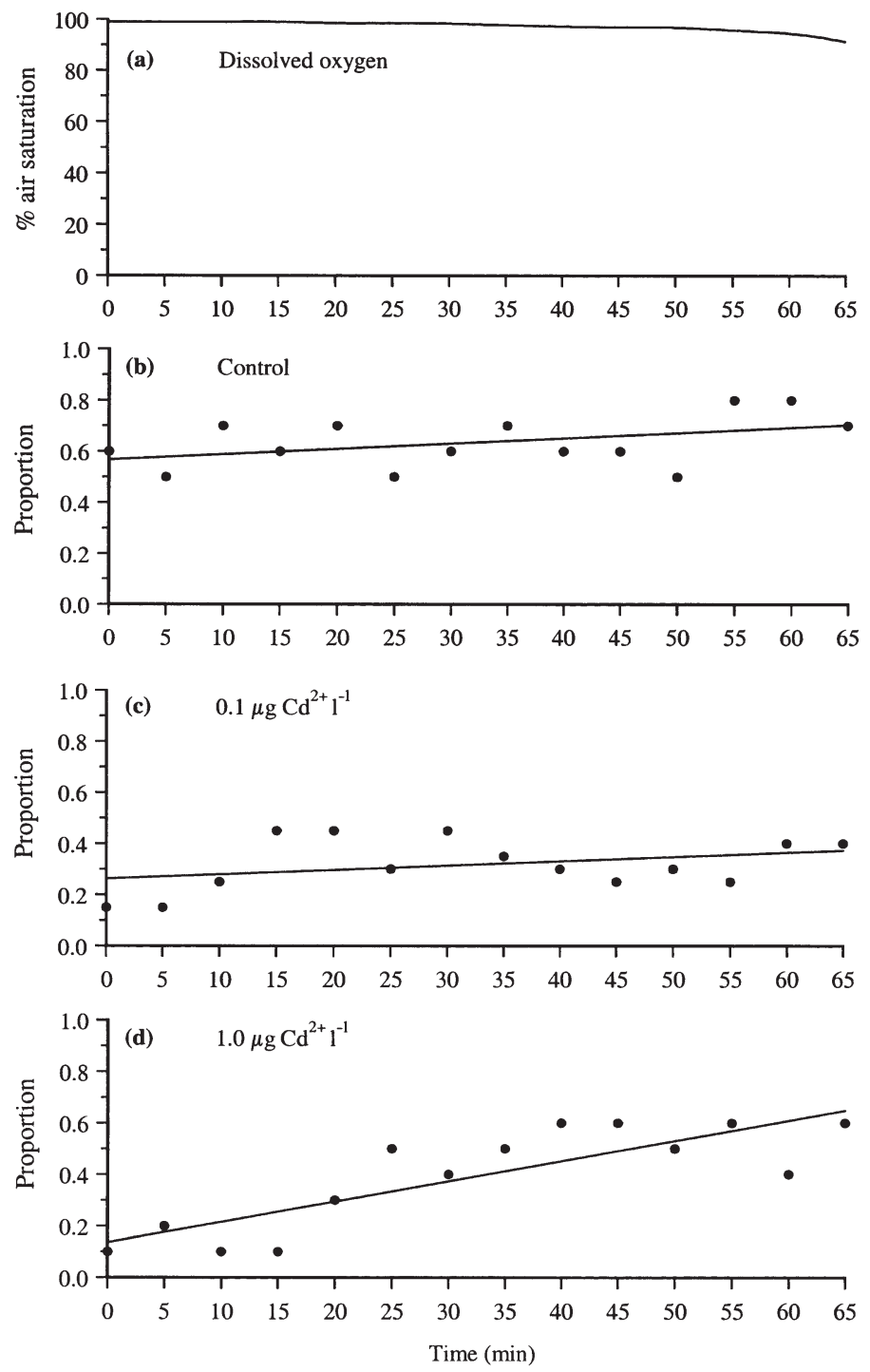

Fig. 8. Neomysis integer. Proportion distributed at the hypoxic end of the DO gradient. (a) DO concentration (\% air saturation) with time; (b) non-exposed $N$. integer; (c) $N$. integer pre-exposed to $0.1 \mathrm{\mu g} \mathrm{Cd}^{2+} \mathrm{l}^{-1}$ for $7 \mathrm{~d}_{i}$ (d) $N$. integer preexposed to $0.5 \mu \mathrm{g} \mathrm{Cd}^{2+} \mathrm{l}^{-1}$ for $7 \mathrm{~d}$. ( $\mathrm{n}=100$ for each dataset)

can recover from this state, in the natural environment the animal would be unable to detect and escape from predators, or maintain position within the estuary. Consequently, the $\mathrm{ET}_{50}$ for hypoxia presented here effectively represents the 'ecological death' of $N$. integer (Roast et al. 2000b). Literature data suggest that crustaceans are generally sensitive to hypoxia. Examples include the amphipod Monoporeia affinis (Sandberg-Kilpi et al. 1999), Nordic krill Meganyctiphanes norvegica (van den Thillart et al. 1999) and the brown shrimp Crangon crangon (Hagerman \& Szaniawaska 1986); however, to our knowledge, there are no published data on tolerance to hypoxia for other mysid species. At DO concentrations below $30 \%$ air saturation $\left(89.0 \mu \mathrm{mol} \mathrm{O}_{2} \mathrm{l}^{-1}\right)$, survival of $N$. integer was poor, with an $\mathrm{ET}_{50}$ of just under $5 \mathrm{~min}$. Pre-exposure to $\mathrm{Cd}$ reduced significantly the tolerance of $N$. integer to hypoxia, and $\mathrm{ET}_{50}$ estimates for Cd-exposed mysids were lower than control animals at all test DO concentrations. However, the response to hypoxia did not show a simple $\mathrm{Cd}$ concentration-dependent relationship. As the concentrations of Cd used in the present study have been recorded in upper estuaries (see Roast et al. 2000b), our data indicate that these Cd concentrations will impair the ability of $N$. integer to with-
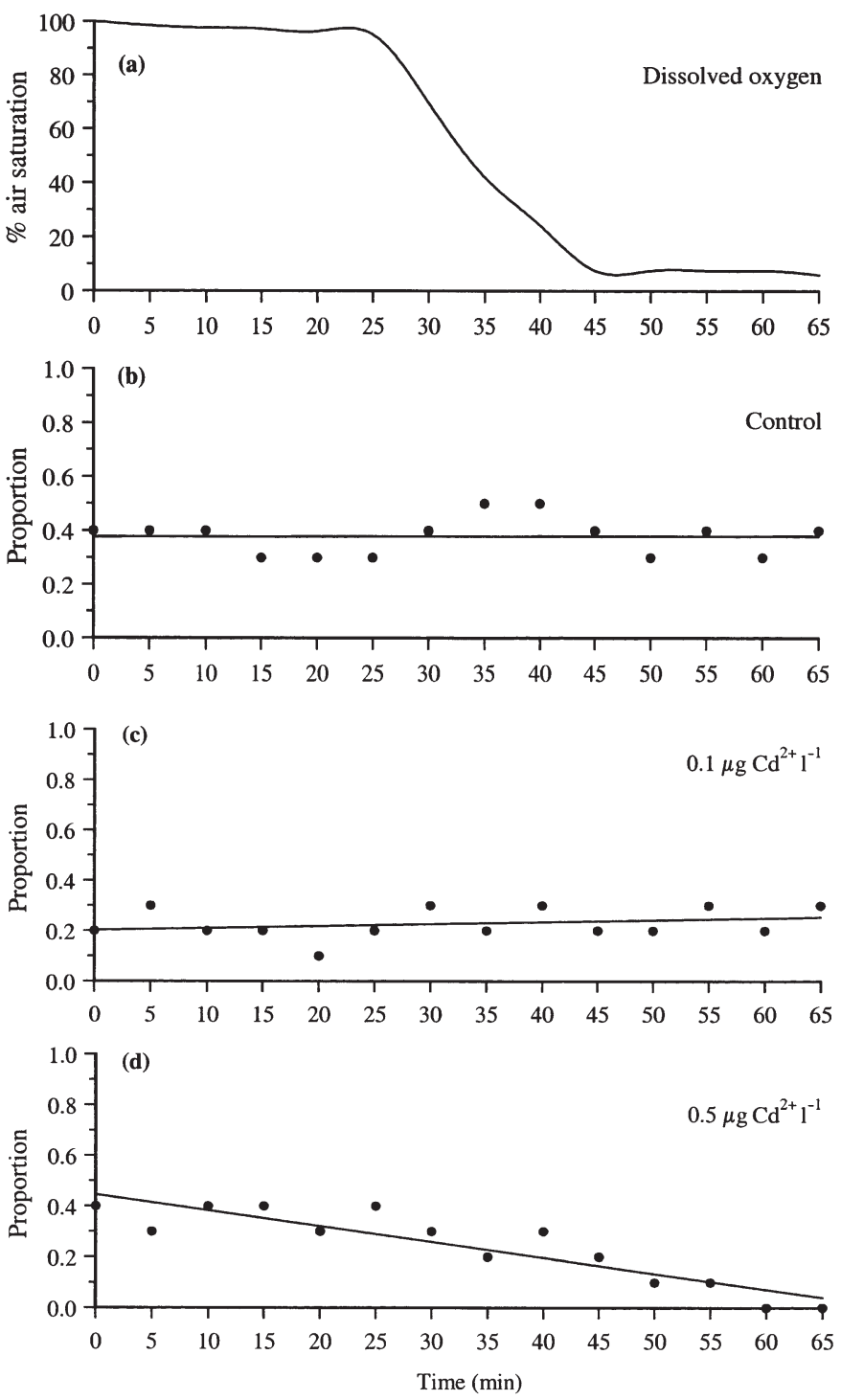

Fig. 9. Neomysis integer. Proportion distributed at oxygenated end of dissolved oxygen gradient. (a) DO concentration (\% air saturation) with time; (b) unexposed $N$. integer; (c) N. integer pre-exposed to $0.1 \mathrm{\mu g} \mathrm{Cd}^{2+} \mathrm{l}^{-1}$ for $7 \mathrm{~d}$ (d) $N$. integer preexposed to $1.0 \mu \mathrm{g} \mathrm{Cd}^{2+} \mathrm{l}^{-1}$ for $7 \mathrm{~d}$. ( $\mathrm{n}=100$ for each dataset) 
stand hypoxia in the field. The mechanistic intepretation for the effects of $\mathrm{Cd}$ on reducing the tolerance of $N$. integer to hypoxia are unclear. Trace metal exposure often leads to damage of gill membranes in crustaceans; for example, copper damages the gills of Carcinus maenas (Lawson et al. 1995, Hebel et al. 1999). Metal-induced damage to the respiratory surface might explain some of the trends in the present data. Pre-exposure to $\mathrm{Cd}$ reduced the number of mysids swimming forward into the current at $100 \%$ air saturation to ca. $20 \%$, compared with ca. $65 \%$ of unexposed mysids. At $50 \%$ air saturation, only $20 \%$ of unexposed mysids swam forward into the current, i.e. the same response recorded for Cd-exposed mysids at $100 \%$ air saturation. Thus, pre-exposure to $\mathrm{Cd}$ appears to induce a state of hypoxia in mysids, even though they are in a normoxic environment. Similar results have been published for krill (Spicer \& Weber 1992) and the shore crab (Nonnette et al. 1993). It is important to note, however, that $N$. integer lacks gills, as do all mysids of the sub-order Mysida (Tattersall \& Tattersall 1951); there are no data available to confirm that trace metals damage the respiratory tissues of mysids. However, pre-exposure to $\mathrm{Cd}$ has been shown to decrease the respiration rate of the mysid Leptomysis lingvura (Guady et al. 1991). If the respiration rate of $\mathrm{Cd}$-exposed mysids decreases, the reduction of tolerance to hypoxia may reflect adverse effects on aspects of the respiratory system and efficiency of gas exchange processes (e.g. ventilation, gas movement across membranes or blood circulation).

In the natural environment, mysids are not restricted by the confines of an experimental vessel but are free to move about, and it is expected that Neomysis integer will migrate away from hypoxia, as reported for other mobile crustaceans (Hagerman \& Szaniawska 1986, Hebel et al. 1997). Results from the current study demonstrate that $N$. integer is sensitive to hypoxia (i.e. $<30 \%$ air saturation) but shows no immediate behavioural response to avoid areas of severe hypoxia (i.e. $10 \%$ air saturation). Mysids migrated in and out of regions with low DO, but did not remain in them for long periods of time (i.e. maximum duration of ca. $120 \mathrm{~s}$ ). Furthermore, when exposed to severe hypoxia in an open-topped aquarium, $N$. integer swam upside down, 'hanging' from the air/water interface (pers. obs.). Such behaviour provides $N$. integer access to the higher DO concentrations present in the air/water interface. The presence of $N$. integer in areas of severe hypoxia for short durations indicates an ability to withstand short episodes of hypoxia typical of its estuarine habitat. A similar response has been reported from field studies of Nordic krill Meganyctiphanes norvegica (Spicer et al. 1999). During vertical migrations in Norwegian fjords, $M$. norvegica swims to depths of $>70 \mathrm{~m}$ where DO concentrations are too low for aerobic metabolism (Spicer et al. 1999). The respiratory physiology of $M$. norvegica is not well suited to anaerobic metabolism and, to occupy these hypoxic waters, they must be close to their physiological limits (Spicer et al. 1999). The fact that $M$. norvegica continues to migrate regularly into hypoxic waters demonstrates the strength of the migratory rhythm and the impetus to enter hypoxic waters (e.g. avoid predators; Spicer et al. 1999). Periods of hypoxia that are likely to cause behavioural responses in $N$. integer have been recorded in estuaries, usually associated with the MTZ. Mysids were susceptible to DO concentrations of $20 \%$ air saturation $\left(\mathrm{ET}_{50}\right.$ of ca. $\left.5 \mathrm{~min}\right)$; however, the present study also showed $N$. integer to enter areas where DO concentrations are $<10 \%$ air saturation for short periods of time. In the natural environment, it is unclear whether mysids would migrate away from such oxygen sags, or tolerate them for short time periods (in a large estuary, the MTZ, and by association the oxygen sag, moves up and down the river as the tide floods and ebbs). Interestingly, $N$. integer is particularly associated with the MTZ of western European estuaries (Mees et al. 1994). Stomach content analyses of $N$. integer suggest that this mysid species feeds on detritus and sediment flocs found in the MTZ (Fockedey \& Mees 1999), and it may be that there is a metabolic trade-off between the physiological demands of inhabiting a hypoxic environment and the energetic gain of feeding in the MTZ. Regardless of the advantages and/or disadvantages of entering this hypoxic area, $\mathrm{Cd}$ induced an avoidance response in $N$. integer presented with a gradient of DO, and Cd-exposed mysids did not enter areas of low DO, even for short time periods. In the natural environment, therefore, mysids exposed to $\mathrm{Cd}$ might be more susceptible to oxygen sags than non-exposed mysids. Consequently, this might affect mysid distribution in the estuary or prevent $N$. integer from feeding in the MTZ.

At a current velocity of $6 \mathrm{~cm} \mathrm{~s}^{-1}$, a speed well within the current velocities experienced by Neomysis integer in the natural environment (Roast et al. 1998), control mysids swam forward into the current. Positive rheotaxis is a normal behavioural response of $N$. integer (Roast et al. 1998). When faced with increasing current speeds, $N$. integer still showed a rheotaxic response; however, at velocities above $10 \mathrm{~cm} \mathrm{~s}^{-1}$, mysids were unable to swim forward against the flow and tended to maintain position instead (Roast et al. 1998). In the present study, as DO concentration decreased, fewer mysids were able to swim forward into a current of $6 \mathrm{~cm} \mathrm{~s}^{-1}$ and a higher proportion of mysids maintained position. Hence, the response to decreasing DO (at constant current velocity) is similar 
to that of mysids experiencing increasing current velocity. The most obvious reason for this response is fatigue, where mysids are no longer able to swim forward into the current, but maintain position, eventually being swept with the current. For example, $50 \%$ of mysids were swept with the current at a DO concentration of $30 \%$ air saturation. The ecological implications of hypoxia-induced fatigue include being swept from optimum areas of the estuary (i.e. for feeding in the MTZ) or increased vulnerability to predators (Roast et al. 2001).

There were significant effects of pre-exposure to $\mathrm{Cd}$ on mysid swimming behaviour in the flume; however, this was independent of DO concentration. For example, although the proportion of mysids exposed to $1.0 \mu \mathrm{g} \mathrm{Cd}^{2+} \mathrm{l}^{-1}$ swimming forward into the current at any given DO concentration was significantly lower than control mysids, progressive hypoxia had no significant effect on this behaviour (until DO concentrations $<60 \%$ air saturation). Furthermore, there was no effect of progressive hypoxia on the proportion of $\mathrm{Cd}$ exposed mysids maintaining position until DO concentrations of $<60 \%$ air saturation were experienced. Again, there was a significant effect of pre-exposure to $\mathrm{Cd}$ on mysid behaviour and, between DO concentrations of 100 and $60 \%$ air saturation, significantly more Cd-exposed mysids maintained position compared with control mysids. Results from the present study suggest, therefore, that the effects of $\mathrm{Cd}$ on mysid swimming ability are greater than those imposed by progressive hypoxia or the physiological demands associated with hypoxia.

In summary, Neomysis integer was intolerant of hypoxia (i.e. $<30 \%$ air saturation). Furthermore, hypoxia ( $<50 \%$ air saturation) reduced the ability of $N$. integer to swim forward into a current, an inherent behavioural trait helping to maintain this mysid species in the upper reaches of European estuaries (Roast et al. 1998). However, N. integer did not avoid areas of severe hypoxia (i.e. $10 \%$ air saturation) and the present study suggests that DO concentrations do not dictate the distribution of $N$. integer in the natural estuarine environment. Pre-exposure to $\mathrm{Cd}(7 \mathrm{~d})$ reduced significantly the tolerance of $N$. integer to hypoxia and induced an avoidance reaction to DO concentrations $<70 \%$ air saturation. The effect of $\mathrm{Cd}$ on mysid swimming ability (Roast et al. 2001) was stronger than the effect of hypoxia on the rheotaxic response of $N$. integer. Given that by inhabiting or moving through the MTZ $N$. integer is likely to experience periods of hypoxia, the present study suggests that $\mathrm{Cd}$ pollution (at current environmental concentrations for some industrial estuaries) will disrupt the ability of $N$. integer to maintain position in its optimum region of estuaries.

\section{LITERATURE CITED}

DeLisle PF, Roberts MH Jr (1994) The effect of salinity on cadmium toxicity in the estuarine mysid Mysidopsis bahia: roles of osmoregulation and calcium. Mar Environ Res 37: $47-62$

Eyre B (1998) Transport, retention and transformation of material in Australian estuaries. Estuaries 21:540-551

Fockedey N, Mees J (1999) Feeding of the hyperbenthic mysid Neomysis integer in the maximum turbidity zone of the Elbe, Westerschelde and Gironde estuaries. J Mar Syst 22:207-228

Gaudy R, Guérin JP, Kerambrun P (1991) Sublethal effects of cadmium on respiratory metabolism, nutrition, excretion and hydrolyse activity in Leptomysis lingvura (Crustacea: Mysidacea). Mar Biol 109:493-501

Hagerman L (1998) Physiological flexibility: a necessity for life in anoxic and sulphidic habitats. Hydrobiology 375/ 376:241-254

Hagerman L, Szaniawska A (1986) Behaviour, tolerance and anaerobic metabolism under hypoxia in the brackishwater shrimp Crangon crangon. Mar Ecol Prog Ser 34: 125-132

Hebel DK, Depledge MH, Jones MB (1997) Responses of crustaceans to contaminant exposure: a holistic approach. Est Coast Shelf Sci 44:177-184

Hebel DK, Jones MB, Moate RM, Depledge MH (1999) Differing sensitivities of respiratory and osmoregulatory gill tissue of Carcinus maenas (Crustacea: Decapoda) to water-borne copper. Mar Biol 133:675-681

Irigoien X, Post J, Castel J, Pfeiffer KF, Hellmann B (1999) Nycthemeral variations of the dissolved oxygen concentration in the turbidity maximum of three European estuaries: biological vs. physical processes. J Mar Syst 22: 173-177

Lawson SL, Jones MB, Moate RM (1995) Effect of copper on the ultrastructure of the gill epithelium of Carcinus maenas (Decapoda: Brachyura). Mar Pollut Bull 31:63-72

Little C (2000) The biology of soft shores and estuaries. Oxford University Press, Oxford

McLusky DS (1989) The estuarine ecosystem, 2nd edn. Blackie Publishers, London

Mees J, Jones MB (1997) The hyperbenthos. Oceanogr Mar Biol Annu Rev 35:221-255

Mees J, Abdulkerim Z, Hamerlynck O (1994) Life history, growth and production of Neomysis integer in the Westerschelde estuary (S.W. Netherlands). Mar Ecol Prog Ser 109:43-57

Mitchell SB, West JR, Guymer I (1999) Dissolved-oxygen/ suspended-solids concentration relationships in the upper Humber Estuary. J Chart Inst Water Environ Manage 13: 327-337

Nonnotte L, Boitel F, Truchot JP (1993) Waterborne copper causes gill damage and haemolymph hypoxia in the shore crab Carcinus maenas. Can J Zool 71:1569-1576

Rainbow PS (1997) Ecophysiology of trace metal uptake in crustaceans. Estuar Coast Shelf Sci 44:169-175

Roast SD, Widdows J, Jones MB (1998) The position maintenance behaviour of Neomysis integer (Peracarida: Mysidacea) in response to current velocity, substratum and salinity. J Exp Mar Biol Ecol 220:25-45

Roast SD, Widdows J, Jones MB (1999) Respiratory responses of the estuarine mysid Neomysis integer (Peracarida: Mysidacea) in relation to a variable environment. Mar Biol 133:643-650

Roast SD, Widdows J, Jones MB (2000a) Egestion rates of the estuarine mysid Neomysis integer (Peracarida: Mysidacea) 
in relation to a variable environment. J Exp Mar Biol Ecol 245:69-81

Roast SD, Widdows J, Jones MB (2000b) Mysids and trace metals: disruption of swimming as a behavioural indicator of environmental contamination. Mar Environ Res 50: 107-112

Roast SD, Widdows J, Jones MB (2001) Impairment of mysid (Neomysis integer) swimming ability: an environmentally realistic assessment of the impact of cadmium exposure. Aquat Toxicol 52:217-227

Sandberg-Kilpi E, Vismann B, Hagerman L (1999) Tolerance of the Baltic amphipod Monoporeia affinis to hypoxia, anoxia and hydrogen sulfide. Ophelia 50:61-68

Spicer JI, Weber RE (1992) Respiratory impairment by waterborne copper and zinc in the edible crab Cancer pagurus (L) (Crustacea, Decapoda) during hypoxic exposure. Mar Biol 112:429-435

Spicer JI, Thomasson MA, Strömberg JO (1999) Possessing a poor anaerobic capacity does not prevent the diel vertical migration of Nordic krill Meganyctiphanes norvegica into hypoxic waters. Mar Ecol Prog Ser 185:181-187

Editorial responsibility: Otto Kinne (Editor),

Oldendorf/Luhe, Germany
Tattersall WM, Tattersall OS (1951) The British Mysidacea. The Ray Society Series, No. 136. Bartholomew Press, Dorking

Turner DR, Whitfield M, Dickson AG (1981) The equilibrium speciation of dissolved components in freshwater and seawater at $25^{\circ} \mathrm{C}$ and $1 \mathrm{~atm}$ pressure. Geochim Cosmochim Acta 45:855-881

Uncles RJ, Joint I, Stephens JA (1998) Transport and retention of suspended particulate matter and bacteria in the Humber-Ouse Estuary, United Kingdom, and their relationship to hypoxia and anoxia. Estuaries 21:597-612

van den Thillart G, George RY, Strömberg JO (1999) Hypoxia sensitivity and respiration of Meganyctiphanes norvegica from Gullman Fjord, Sweden. Sarsia 84: 105-1-9

Widdows J, Brinsley M, Bowley N, Barrett C (1998) A benthic annular flume for in situ measurement of suspension feeding/biodeposition rates and erosion potential of intertidal cohesive sediments. Est Coast Shelf Sci 46:27-38

Wright DA (1995) Trace metal and major ion interactions in aquatic organisms. Mar Pollut Bull 31:8-18

Submitted: September 20, 2001 Accepted: January 29, 2002 Proofs received from author(s): June 17, 2002 